\title{
O céu onde relampeja a memória
}

\author{
Isabel Almeida Carneiro' e Jacqueline de Moura Siano"
}

Resumo: $\mathrm{O}$ artigo busca traçar conceitos que foram motivados pela pandemia da Covid-19 surgida em 2020, a partir das falas de Paul Preciado, Achille Mbembe, Boaventura de Sousa Santos e Ailton Krenak. Os autores produziram pensamentos emergenciais e uma subteorização, segundo o próprio Sousa Santos, do momento em que vivemos. O texto também foi construído a partir das ideias da passagem entre sociedade soberana e disciplinar de Michel Foucault e de um pequeno lampejo presente na "filosofia da história" de Walter Benjamin.

Palavras-chave: vírus. biopolítica. subteorização. isolamento.

\section{The heaven where the memory flies}

\begin{abstract}
The article seeks concepts that were motivated by the Covid-19 pandemic in 2020 from the speeches of Paul Preciado, Achille Mbembe, Boaventura de Sousa Santos and Ailton Krenak. The text was also constructed from the ideas by Michel Foucault and a small glimpse present in Walter Benjamin's "philosophical history".
\end{abstract}

Keywords: virus. biopolitcs. under-theorization. isolation.

I Artista, pesquisadora e professora. Doutora pelo PPGAV/EBA/UFRJ em 2015 na linha de pesquisa em Linguagens Visuais. Mestre pelo PPGArtes em 2010 com o trabalho sobre "Notas-colagem". Professora do Departamento de Ensino da Arte e Cultura Popular do Instituto de Artes da UERJ. Vínculo institucional: Universidade do Estado do Rio de Janeiro, Rua São Francisco Xavier, 524. Maracanã - Rio de Janeiro, RJ, 20943-000. E-mail: bebelcarneirogm@gmail.com. ORCID https://orcid.org/00000003-2054-5705. Lattes iD: http://lattes.cnpq.br/4988281259224394. Rio de Janeiro, Brasil. Nome da autora para citação: CARNEIRO, I. A.

II Artista-pesquisadora. Pós-doutoranda (CAPES-PNPD), doutora (2017) e mestre (2010) em Artes pelo PPGArtes-UERJ. Vínculo institucional: Professora da Escola de Artes Visuais do Parque Lage (EAV-Parque Lage) desde 2005. E-mail: jacquelinesiano@gmail.com. ORCID https://orcid.org/0000-0002-3937-0004. Lattes iD: http://lattes.cnpq. br/7451591713512786. Rio de Janeiro, Brasil. Nome da autora para citação: SIANO, J. de Moura. 
Segundo Michael Löwy (2005) o que Walter Benjamim rejeita no historicismo é a conformidade com a representação do passado entendida como uma ininterrupta transmissão de fatos que se sucedem. Nas teses Sobre o conceito de história de Benjamin não é através do fluxo da história que seremos capazes de conhecer o passado, mas através de lampejos de acontecimentos do passado "apoderar-se de uma lembrança tal como ela lampeja num instante de perigo" (p. 65) onde a memória é o céu em que rebrilha uma centelha que nos alerta sobre o perigo que corremos; "esse momento único, essa ocasião fugaz e precária de salvação (Rettung), antes que seja demasiadamente tarde" (ibidem, p. 66).

Qual a necessidade de ainda pensarmos filosoficamente o momento de excepcionalidade que estamos vivendo? Nesses momentos de desamparo, de tristeza e de confusão nos deparamos com textos de intelectuais que admiramos. Mas por que achamos tão importante esses textos? Por que passamos a lê-los? O que nos leva à procura de uma leitura intelectualizada acerca da Covid-19 num momento de caos planetário; caos gerado ironicamente por um organismo leve, transparente, que flutua no ar, pronto para invadir corpos humanos e se alojar nos pulmões, impossibilitando a respiração, matando por sufocamento. Um vírus que só ataca os humanos. Um clamor enviado pelo planeta, como nos alerta Ailton Krenak (2020). Talvez a resposta resida na nossa própria dificuldade de avaliação distanciada do momento crítico no qual estamos todos submersos, e assim como eles, buscamos dar prosseguimento aos nossos pensamentos e ações no mundo. Estamos nos deparando com fronteiras físicas, sociais e psíquicas, e esses textos nos possibilitam adentrar um campo diáfano posto pelo mais enfático momento de interrupção dos fluxos de nossas vidas contemporâneas; de chegada à clareira da nossa existência. Estamos, pois, desenvolvendo a subteorização proposta por Boaventura de Sousa Santos (2020).

O problema é que a prática caótica e esquiva dos dias foge à teorização e exige ser entendida em modo de subteorização. Ou seja, como se a claridade da pandemia criasse tanta transparência que nos impedisse de ler e muito menos reescrever o que fôssemos registando no ecrã ou no papel. (p. 14)

Essa claridade dos dias, e que nos cega, remete-nos ao ensaio de Giorgio Agamben O que é o contemporâneo? (2010). No texto o filósofo italiano nos convida a refletir sobre a impossibilidade de vivermos ajustados aos domínios de nosso próprio tempo. É o lampejo do passado, a intempestividade com que o não vivido nos atravessa no aqui-agora de nossas vidas cotidianas, que nos faz enxergar as mazelas do nosso próprio tempo. O calor da hora nos desorienta e impede que sejamos capazes de perceber nossas urgências. Assim também percebem os pensadores que acolhemos em diálogo. 


\section{Lições disciplinares para domar corpos esquivos}

Em 18 de março seguíamos o rumo da disciplina da pós-graduação ${ }^{1}$ (PPGArtes-UERJ) com uma ementa que trazia questões de outras epistemologias; mais ao sul e transgressoras. Uma bibliografia composta majoritariamente por intelectuais mulheres e negras; leituras que se propõem antirracistas, antissexistas e antilesbofóbicas. Interessavam-nos, então, os estudos da mulher, a epistemologia que contesta o patriarcado, o colonialismo e o racismo estrutural que permeia as relações sociais no Brasil.

O primeiro texto que lemos foi Aprendendo com o vírus (on-line, 2020) de Paul Preciado que inicia sua reflexão com Michel Foucault e o desenvolvimento de técnicas de controle e dominação dos corpos desde a "sociedade soberana" se afirma na "sociedade disciplinar", e que hoje soa como um alerta sobre como uma epidemia pode radicalizar as técnicas de biopolíticas. Técnicas de contenção de fluxos e de disciplinamento, utilizadas em países do Oriente, como China e Coréia do Sul, e que serviram de exemplo de eficácia no controle e combate ao coronavírus em outros países e continentes, ainda que resguardadas as divergências culturais. ${ }^{2}$

Segundo Foucault (1987), a transição da sociedade soberana para a sociedade disciplinar se inicia no século XVII, e aos poucos vai transformando o corpo humano num campo de poder modelado, ajustado e disciplinado pelas instituições hospitalares, militares, escolares... Na passagem

1 Hoje, revisitando a ementa do curso compreendemos ainda mais a urgência de pensarmos mundos possíveis durante e depois da Covid-19, ainda mais diante dos resultados de pesquisas que apontam para a faixa social mais atingida e revelam a preocupação de pesquisadores e pesquisadoras com os habitantes das áreas com alta densidade demográfica, como favelas e comunidades que orbitam os centros urbanos. Regiões assoladas pela violência do tráfico de drogas, das milícias e da própria polícia. Regiões onde a precariedade dos serviços sociais e sanitários, a péssima qualidade das habitações e a falta de saneamento dificultam o isolamento. Pessoas que se veem sujeitas a buscar recursos financeiros em trabalhos precários e subempregos, expondo os privilégios de parte da sociedade que pode se recolher em suas casas se esquivando da contaminação. O site Observatório das Favelas publica o mapeamento da disseminação, do contágio, número de óbitos e de letalidade da no município do Rio de Janeiro. No Portal da Fundação Oswaldo Cruz (FIOCRUZ) encontramos um artigo intitulado "Desigualdade social e econômica em tempos de Covid-19 (13/05/2020) que revela a preocupação do Conselho Nacional de Saúde (CNS) com a população em "situação de rua, com sofrimento ou transtorno mental, com deficiência, vivendo com HIV/Aids, LGBTQI+, população indígena, negra e ribeirinha e trabalhadores do mercado informal, como catadores de lixo, artesãos, camelôs e prostitutas." Para o artigo na íntegra, acessar: https://portal.fiocruz.br/noticia/ desigualdade-social-e-economica-em-tempos-de-covid-19. Acesso em: 22 set. 2020.

2 Para maiores informações sobre as divergências entre Oriente e Ocidente em face ao novo coronavírus sugerimos a leitura de artigo do filósofo sul-coreano Byung-Chul Han. Disponível em: http://www.ihu.unisinos.br/78-noticias/597343-o-coronavirus-de-hoje-e-o-mundo-de-amanha-segundo-o-filosofo-byung-chul-han Acesso em: 18 ago. 2020. 
da sociedade soberana para a sociedade disciplinar as técnicas e dispositivos de controle se sofisticam e esses mesmos corpos são transformados em máquinas de produtividade. Processo que tende a controlar o corpo social como um todo. O corpo humano entra numa maquinaria de poder que o esquadrinha, o desarticula e o recompõe.

Até o séc. XVIII, no poder soberano, o corpo dos indivíduos é essencialmente a superfície de inscrição de suplícios e penas. Já nas instâncias de controle que surgem nas sociedades disciplinares a partir do séc. XIX, o corpo adquire uma significação totalmente diferente; ele não é mais o que deve ser suplicado, mas o que deve ser formado, reformado, corrigido; deve adquirir aptidões, receber um certo número de qualidades, qualificar-se como corpo capaz de trabalhar.

A atenção será um tema importante na sociedade disciplinar, pois é a partir da atenção localizada no corpo que as formas de produtividade do capitalismo ganham força. A atenção e a dispersão são anexadas e controladas por técnicas de manipulação com a introdução ininterrupta de novos produtos, novas fontes de estímulos e fluxos de informações capaz de adquirir métodos de administrar e regular a percepção.

Na passagem do século XIX para o século XX o poder disciplinar pretende potencializar as energias do corpo numa esfera de controle panopticista. A disciplina passa a fabricar corpos submissos e a aumentar as forças do corpo em termos econômicos e de utilidade. O panopticismo torna-se então um dos traços característicos da sociedade disciplinar; uma forma de poder que se exerce sobre os indivíduos em forma de vigilância individual e contínua. $\mathrm{O}$ biopoder se dissemina por toda a sociedade como forma de administração das potencias do corpo. O que se entende por biopoder são técnicas e táticas de administração do corpo. Nunca a disciplina foi tão importante, tão valorizada quanto a partir do momento em que se procurou gerir a população.

Na sociedade disciplinar, gerir a população significa guia-la em profundidade, minuciosamente, no detalhe. A ideia de um novo governo da população torna ainda mais agudo o problema do fundamento da soberania, e ainda mais necessário se desenvolver a disciplina como forma de controlar a população. Devemos compreender essa transformação não em termos de substituição de uma sociedade soberana para uma sociedade disciplinar, e desta para uma sociedade de governo, mas em termos de uma triangulação: soberania-disciplina-gestão governamental, que tem na população seu alvo principal e nos dispositivos de segurança seus mecanismos essenciais. 
A mudança que se processou da sociedade soberana para a sociedade disciplinar foi que o conjunto de instituições, procedimentos, análises e táticas tiveram por objetivo gerir a população. O que acontecia no governo soberano era a tentativa de açambarcar mais do que organizar a produção, decidir sobre a morte mais do que gerir a vida. A sociedade disciplinar se torna descentralizada, suas formas de controle partem das diversas instituições que regulamentam os indivíduos.

O poder disciplinar na passagem do séc. XIX para o XX tem como modelos a prisão, o colégio, os quartéis e os manicômios. Faz-se necessário administrar corpos com a racionalização do espaço. Para isso ele utiliza diversas técnicas. Os espaços institucionais como a prisão e o manicômio são também espaços discursivos, espaços normativos. Enquanto o manicômio é um poder científico, a prisão é um poder jurídico, e ambos são processos de normatização dos corpos. A fábrica, a escola, a prisão e os hospitais têm por objetivo ligar o indivíduo a um processo de produção, de formação ou de correção. Vejamos o que Foucault fala desses espaços institucionais:

\begin{abstract}
Mas o princípio de "clausura" não é constante, nem indispensável, nem suficiente nos aparelhos disciplinares. Estes trabalham o espaço de maneira muito mais flexível e mais fina. E em primeiro lugar segundo o princípio da localização imediata ou do quadriculamento. Cada indivíduo no seu lugar; e em cada lugar, um indivíduo. Evitar as distribuições por grupos; decompor as implantações coletivas; analisar as pluralidades confusas, maciças ou fugidias. O espaço disciplinar tende a se dividir em tantas parcelas quanto corpos ou elementos há a repartir. É preciso anular os efeitos de repartições indecisas, o desaparecimento descontrolado dos indivíduos, sua circulação difusa, sua coagulação inutilizável e perigosa; tática de antideserção, de antivadiagem, de antiaglomeração. Importa estabelecer as presenças e as ausências, saber onde e como encontrar os indivíduos, instaurar as comunicações úteis, interromper as outras, poder a cada instante vigiar o comportamento de cada um, apreciá-lo, sancioná-lo, medir as qualidades ou os méritos. Procedimento, portanto, para conhecer, dominar e utilizar. A disciplina organiza um espaço analítico. (FOUCAULT, 1987, p. 123)
\end{abstract}

O corpo não é somente controlado pela localização no espaço, mas também pela distribuição do tempo. A questão é como capitalizar o tempo dos indivíduos, acumulá-lo em cada um deles, em seus corpos, em suas forças e capacidades, e de maneira que seja suscetível de utilização e de controle. Como organizar as durações rentáveis? As disciplinas, que analisam o espaço, que decompõem e recompõem as atividades, devem ser também compreendidas como aparelhos para adicionar e capitalizar o tempo. Na sociedade moderna do séc. XIX o controle não é mais espacial, e sim temporal. O que se pretende é o controle do tempo dos indivíduos, que é também o tempo de produção nas sociedades industriais. É preciso que o tempo dos homens seja oferecido ao aparelho de produção; que o aparelho de produção possa utilizar o tempo de vida. 
No século XIX surge também a fisiologia preocupada com a dinâmica do corpo no trabalho. As práticas sexuais são estudadas como funções com ênfase na biologia e programas de eugenia para a constituição de seres humanos perfeitos. Pessoas albinas, com elefantíase são consideradas pessoas anormais; segregadas são enviadas para manicômios a fim de serem observadas e servirem como objetos de estudos e análises científicas. Gille de La Tourette, por exemplo, publica em 1886 seu Études cliniques et physiologique sur la marche em que apresenta os resultados de suas observações desordens psicomotoras a partir da impressão dos passos de pacientes do Hospitaux de Paris et la Salpetrière. No Brasil do século XIX, mais precisamente no ano de 1889 , começa a funcionar no Rio de Janeiro, um gabinete antropométrico baseado no método especulativo de identificação de criminosos do criminalista Alphonse Bertillon. Importam-se instrumentos de medição (antropômetros e catetrômetros) e livros especializados nos "estudos" bizarros realizados a partir de características físicas dos corpos de criminalizados, incluindo-se aí suas tatuagens, que definiriam os homus crimilales. Especulações que associam medições e características físicas a cálculos comprobatórios dessas associações entre anatomia e comportamento psicossocial. Trata-se do esquadrinhamento do corpo humano e da biologização da interioridade psicológica, na canalização dos instintos, insistindo-se em vários tipos de normatização dos corpos. Também passam a se considerar anormais aqueles que apresentam condutas desviantes e praticantes de uma sexualidade diversa do padrão heteronormativo. No século XX, George Bataille e Antonin Artaud reivindicam a liberdade de práticas sexuais promovendo experiências anárquicas.

Na obra de Georges Bataille predomina a ultrapassagem dos limites corporais. O que se procura são corpos não dóceis, livres do adestramento, da disciplina, da formatação empregada pelas técnicas do biopoder. Para Bataille, os séculos XIX e XX assistiram a uma racionalização da crueldade, por isso o autor expões seu interesse pelos suplícios e sacrifícios do corpo utilizados como forma de punição mais expressiva ao prazer. Existe em sua obra a busca de uma libertação do corpo por via do erotismo ligado à morte, como nas orgias sangrentas narradas em cenas de História do Olho (1928) e outras tantas em que invoca a tortura e o suplício, investindo na transgressão e no erotismo como princípios de um questionamento sobre o limiar entre o humano e o bestial.

Bataille interessa-se por Sade pelo seu rompimento com o permitido e o proibido, pela sua relação com as experiências místicas e pela concepção do excesso. Sade será o precursor da reivindicação do corpo para além dos seus limites e pelos processos de dessubjetivação. O que interessa a Bataille 
é o limite da linguagem, por isso ele utiliza a dessubjetivação como forma de um jogo com a linguagem, sem nunca ultrapassá-lo. Experiências estáticas como o êxtase, uma experiência religiosa com características profanas compõem esses processos. Em as Lágrimas de Eros (1961), Bataille traça um longo percurso do homem ancestral, que já conhecia a angústia da morte, e faz a ligação da morte com o erotismo e deste com práticas religiosas longínquas. Bataille ultrapassa a linguagem pela via da transgressão dos limites do sujeito, mas essas transgressões não passam pela escrita, e sim, pelas experiências limites dos seus autores escolhidos - como Nietzsche e Sade. Bataille examina o excesso da escrita destes autores e estuda onde estaria este excesso que não se encontra na escrita. Ele se interessa, portanto por tudo que está fora, que escapa; que está no limite do corpo, por experiências interiores capazes de operar um desassujeitamento.

\section{Lições do Coronavírus: isolar para não contaminar corpos imunes}

Paul Preciado (on-line, 2020) explora os conceitos de comunidade e imunidade cuja raiz etimológica se encontra no termo latino múnus, o tributo pago pelo indivíduo ao estado. O corpo "imune" diz respeito ao "agente economicamente livre (masculino, branco, heterossexual)", que não precisa prestar contas à comunidade, enquanto os démunis são os outros corpos; daqueles "excluídos em um ato de proteção imunológica" (ibid., n.p.). Preciado ressalta que é a partir das pesquisas médicas de Louis Pasteur (vacina antirrábica) e Robert Koch (descoberta do bacilo da tuberculose) do século XIX, e da descoberta da primeira vacina contra varíola, que o termo imunidade adentra o âmbito sanitário. Com a ascensão do nazismo, a noção de imunidade racial "sobreviveu na Europa legitimando as políticas neoliberais de gestão de suas minorias radicalizadas e das populações migrantes" (ibid., n.p.). Imunidade que tornou a acentuar as diferenças entre os europeus eles mesmos, e muito mais ainda na relação com os "outros", promovendo e acentuando a estigmatizarão cultural, racial e sexual. Com essas restrições há muito introjetadas, diz Preciado: "A gestão política das epidemias põe em cena a utopia da comunidade e as fantasias de imunidade de uma sociedade, exteriorizando seus sonhos de onipotência (e os fracassos retumbantes) de sua soberania política." (ibid., n.p.).

Para o autor, com a radicalização das técnicas de gestão biopolítica e os saberes acumulados com outras tantas pandemias, a ideia de que o novo coronavírus tenha sido criado em laboratório não passa de uma piada de mau gosto:

[...] o vírus atua à nossa imagem e semelhança, não faz mais do que replicar, materializar, intensificar e estender a toda a população as formas dominantes da gestão biopolítica e necropolítica que já estavam trabalhando no território nacional e em suas fronteiras. (ibid., n.p.). 
Os efeitos danosos de uma epidemia refletem, portanto os investimentos (ou a falta de investimentos) em políticas públicas nacionais e internacionais, ampliando os riscos de exclusão social e cultural, como o reaparecimento do apartheid, o aprofundamento da xenofobia, do racismo, da misoginia e da homofobia, entre outras tantas formas virais de preconceito, que acabam por contaminar mentes mais propensas a acreditar em teorias conspiratórias. Se o combate à epidemia da sífilis, que se estendeu por séculos, e só foi curada com a descoberta da penicilina no ano de 1928, se revela como fruto de uma sociedade mais atenta à saúde e empenhada na libertação sexual, são os movimentos de descolonização, movimentos feministas e LGBTQ+ que mais tarde ratificarão a libertação dos corpos da moral heteronormativa.

A Aids remasterizou e reatualizou a rede de controle sobre o corpo e a sexualidade tecido pela sífilis, e que a penicilina e os movimentos de descolonização, feministas e homossexuais desarticularam e transformaram o corpo e a sexualidade nos anos sessenta e setenta. (ibid., n.p.).

Preciado destaca novas formas de biopoder as nomeando "farmacopornográfico"; formas em que o corpo não é mais regulado pelas instituições disciplinares, mas por um conjunto de tecnologias biomoleculares, microprostéticas, digitais e de transmissão de informação e de técnicas de biovigilância. A emergência de políticas de fronteira, a estrangeirização do outro, o medo do que está de fora, compõem o quadro de gerenciamento da vida das populações.

Preciado identifica duas formas de gestão do coronavírus. Num primeiro momento o controle se aproxima do modelo de gestão operado durante a peste: 0 isolamento doméstico, que retorna aos modelos arquitetônicos dos hospitais analisados por Michel Foucault em Vigiar e Punir (1987) que se configura numa gestão disciplinar. Num segundo momento, e já num estágio mais avançado e contando com o auxílio de modernas técnicas de testagem rápida, as "famacopornográficas de biovigilância" e com dispositivos móveis que são capazes de monitorar em tempo real corpos em movimento (op. cit. n. p.) instalam-se as práticas estatais de biovigilância que no limite, colocam em xeque nossas democracias já um tanto quanto precárias. A estrangeirização, o fortalecimento de barreiras com o intuito de cercear o que vem de fora e impedir a partilha com os indesejados, torna-se uma prática comum nos tempos de pandemia.

Curar-nos a nós mesmos como sociedade significaria inventar uma nova comunidade para além das políticas de identidade e de fronteira com as quais temos produzido a soberania até agora, mas também para além da redução da vida à sua biovigilância cibernética. (PRECIADO, 2020, on-line, n. p.) 


\section{Diante da pandemia em tempo de esgotamentos}

Achille Mbembe em seu artigo pandêmico $O$ direito universal à respiração (2020, on-line, n.p.) disserta sobre o tempo de brutalismo que estamos vivendo, que seria a ênfase na "redistribuição desigual da vulnerabilidade" à qual a Covid-19 impõe ao planeta. "Tempos sem garantia ou promessa, num mundo cada vez mais dominado pelo medo do seu próprio fim" (ibid, n.p.). Força geomórfica que ratifica separações e exclusões que já estavam em curso antes do surgimento da epidemia, criando topologias de vulnerabilidade e de esgotamentos. O que temos hoje são técnicas de fronteirização e a devastação ainda maior de florestas. ${ }^{3}$ Segundo Mbembe não haverá mais comunidade quando não pudermos mais recordar os vivos, as mortes em massa e sem sepultamento acabam por gerar isso. $\mathrm{O}$ em-comum depende da partilha.

Não basta tapar o buraco. No meio da cratera é preciso tudo inventar, a começar pelo social. Pois quando trabalhar, aprovisionar, informar-se, manter o contacto, nutrir e conservar as ligações, conversar e trocar, beber juntos, celebrar o culto ou organizar funerais, não puder ter lugar senão por interpostos écrans, é tempo de tomar consciência de que estamos cercados de anéis de fogo por todo o lado. Em grande medida, o digital é o novo buraco que a explosão criou na terra. Trincheira, entranhas e paisagem lunar ao mesmo tempo, é o bunker onde homem e mulher isolados são convidados a refugiar-se. (ibid., n.p.).

Estamos vivendo um momento de grande separação e confinamento em que o temor de viver se avizinha ao da própria morte. Transformamo-nos em corpo-objeto, corpo-máquina e corpo-digital. O afastamento social que nos é imposto por um organismo invisível, a negação por parte de algumas lideranças políticas e a falta de diligência para a contenção de sua veloz disseminação são fatores que expõe a vulnerabilidade a que todos estamos expostos; a uma ideia de humanidade que deixou atrás de si um rastro de destruição ambiental a nível planetário.

Mbembe coloca-nos algumas questões desconcertantes: Como recompor "uma terra habitável"? "Seremos capazes de redescobrir a nossa pertença

3 Desde o ano de 2019 o Brasil vem assistindo ao aumento desmedido de incêndios florestais, que se acentuaram agora no corrente ano, afetando os mais diversos ecossistemas como a floresta amazônica, o cerrado, a caatinga, o pantanal e a mata atlântica. As imagens veiculadas pelas mídias chocam, enquanto as informações oficiais tentam esconder a tragédia ambiental. Segundo matéria publicada no jornal Estado de Minas, publicada no dia 15 de setembro do corrente ano, que acompanha os dados do Instituto Nacional de Pesquisas Espaciais (Inpe) foram registrados 60.675 incêndios na Amazônia até o dia 14 de setembro. Para ler a matéria, acessar: https://www.em.com. br/app/noticia/nacional/2020/09/15/interna_nacional,1185431/seca-e-o-fogo-criminoso-devastam-quase-todos-os-biomas-do-brasil.shtml Acesso em: 23 set. 2020. 
à mesma espécie e o nosso inquebrantável vínculo à totalidade do vivo?" (2020, on-line, n.p.). Para o autor, com os sistemas de saúde fragilizados, que sofrem processos contínuos de desmonte, especialmente nos países onde se localizam as populações mais vulneráveis; sistemas "devastados por anos de negligência organizada, o pior ainda está por vir." (MBEMBE, 2020, on-line, n. p). Parece-nos então não haver saída ao menos a curto e médio prazo. O medo se alastra mundo afora afirmando uma "desigual vulnerabilidade" (ibid., n.p.). Desigualdade exposta pelo coronavírus que amplifica a violência embutida nessa mesma desigualdade.

O caos está posto e o vírus à espreita. As formas de vida se encontram em acelerado processo de esgotamento por envenenamento. A utilização de produtos químicos de alta toxidade utilizados na exploração de recursos minerais se agrava com a produção de resíduos tóxicos e a monumental quantidade de plástico e outros dejetos lançados nos oceanos e na terra "substâncias e resíduos [que] não atacam apenas a natureza e o ambiente (solo, água, cadeias alimentares), mas igualmente os corpos expostos ao chumbo, ao fósforo, mercúrio, berílio, aos fluidos refrigerantes" (ibid., n.p.). Some-se a isso a decomposição dos corpos e o lixo hospitalar produzido pela pandemia em escala planetária. Corpos sepultados em esquifes lacrados sem a possibilidade de velório e de adeus.

Eis o tempo de implacável destruição, asfixia e putrefação financiado pelo neoliberalismo e pelo deus-dinheiro. Por quanto tempo resistiremos se tudo que tocamos vira veneno? E o vírus? "Não importa o quanto nos tentemos livrar dele. No final, tudo nos traz de volta ao corpo." (ibid., n.p.). Corpo vulnerável, isolado e intoxicante, do qual um simples abraço pode transmitir a morte por asfixia. Para o autor não adianta sonharmos com uma transfiguração pela tela que nos transmite a falsa ideia de fluidez em rede. Teremos que recomeçar, e a partida se dará com a recomposição da Terra. "Seremos capazes de redescobrir a nossa pertença à mesma espécie e o nosso inquebrantável vínculo à totalidade do vivo? Talvez esta seja a derradeira questão, antes que a porta se feche para sempre." (ibid., n. p.)

Ailton Krenak (2020), pensador e ativista ambiental nos alerta para o abismo que cavamos. Segundo o autor, ao promovermos uma extração brutal dos recursos naturais do planeta, o vírus e a Mãe Terra estão nos dando uma resposta. Somos o único ser vivo a sofrer com o novo coronavírus, enquanto os animais e as plantas continuam ilesos e a ganhar espaço. São inúmeros os relatos e imagens de animais ocupando as cidades e retomando espaços e lugares. A suspensão das atividades econômicas e o retorno de algumas espécies, assim como a redução da poluição do ar, nos avisa que sim, podemos preservar o planeta se assim o quisermos. Que podemos sim, "adiar o fim do mundo". 
Os textos de Preciado e Mbembe se tocam num mesmo ponto: a divisão feroz do globo, as técnicas de biovigilância, as linhas de segmentação físicas e biológicas intensificadas. Muitos estados e pessoas buscarão reforçar suas fronteiras, seja da cidade, da rua, do estado, na esperança de proteção contra a exterioridade.

Também em artigo recente Boaventura de Souza Santos discorre sobre a contemporaneidade do coronavírus e começa seu texto falando da normalidade do estado de exceção ou a crise continuada em que estamos atravessando há tempos, e que tem por objetivo a permanência da crise, a legitimação da escandalosa concentração de riqueza e o boicote a medidas eficazes para impedir a iminente catástrofe ecológica. O que Boaventura em seu texto A cruel pedagogia do vírus (2020, on-line) chama de alegoria da pandemia, é que a pandemia do coronavírus provoca o medo caótico e generalizado de uma morte sem fronteiras incitada por um organismo invisível que ataca indiscriminadamente o corpo humano. Alerta para a ideia de normalidade apesar de vivermos desde há muito, num contexto de exceção. Para o autor, a crise do coronavírus "vem apenas para agravar uma situação de crise a que a população mundial tem vindo a ser sujeita." (ibid., p. 6). Se por um lado a pandemia traz um sentimento democrático de solidariedade e compaixão, por outro ela aparta a todos tendo no isolamento a forma de escape à doença. Isolamento desigual que põe em risco certos grupos sociais localizados numa condição social, política e cultural que ele nomeia como "Sul" onde cabem várias categorias subalternizadas como, por exemplo, as mulheres (é fato o aumento de feminicídio e violência doméstica) ${ }^{4}$; os trabalhadores informais em seus trabalhos precarizados (os primeiros atingidos pela diminuição do consumo e que pouco contam com auxílio governamental); os trabalhadores da rua (que dependem do fluxo de transeuntes para seu sustento diário); a população de rua (cuja condição de vida impossibilita por completo o abrigo exigido pela própria quarentena), além de moradores de regiões periféricas das grandes cidades e favelas cujas moradias exíguas impedem o distanciamento físico recomendado; os idosos (especialmente aqueles que vivem no Norte) entre outros tantos como a população carcerária cujo isolamento real em espaço superlotado já traz em si o risco de contaminação. São todos corpos desprezados e abandonados pelas classes privilegiadas e por governos omissos que sempre os trataram como invisíveis. "É possível o auto isolamento num contexto de permanente hetero-isolamento imposto pelo Estado?" questiona Sousa Santos (2020, p.18).

4 Em vários países vem se verificando um aumento significativo de violência doméstica contra mulheres, inclusive de casos de feminicídio, como mostra artigo intitulado "Casos de feminicídio crescem 22\% em 12 estados durante pandemia", publicado em 01 junho 2020, na página da Agência Brasil. Disponível em: https://agenciabrasil.ebc.com.br/direitos-humanos/noticia/2020-06/ casos-de-feminicidio-crescem-22-em-12-estados-durante-pandemia Acesso em 22 set. 2020. 


\section{E haverá uma saída desse labirinto?}

Alguns economistas e governantes clamam pela "volta à normalidade", mas que normalidade é essa? As projeções para o futuro próximo não são nada otimistas; crise ecológica, cataclismos, esgotamentos, novas pandemias, fim da espécie humana e de outras tantas formas de vida que ainda habitam o planeta. Grave é a crise ambiental. Grave é a crise humana. Estamos sufocando a possibilidade de vida no planeta. Nossa casa. Nossa nave mãe. Boaventura, assim como Ailton Krenak acreditam que se persistirmos no modelo do neoliberalismo o fim será inescapável. Concordam com um destino irreversivelmente letal, se continuarmos a violar e a consumir nosso planeta. "Esse pacote chamado de humanidade vai sendo descolado de maneira absoluta desse organismo que é a Terra, vivendo numa abstração civilizatória que suprime a diversidade, nega a pluralidade das formas de vida, de existência e de hábitos." (KRENAK, 2020, p.7). "As pandemias, tal como as manifestações da crise ecológica, são a punição que sofremos por tal violação." (BOAVENTURA, 2020, p. 23). "Não podemos voltar àquele ritmo, ligar todos os carros, todas as máquinas ao mesmo tempo." (KRENAK, op. cit., p.14).

Diante de quadro tão assustador, perguntamo-nos se haverá uma saída para a humanidade. Talvez ela esteja numa virada capaz de nos restituir aquilo que o termo traz em sua raiz etimológica, o húmus; a humildade. Mas teremos tempo?

Em Para alimentar la llama de la esperanza (2020) Souza Santos propõe que pensemos artisticamente uma saída para a América Latina, como forma de embate ao modelo hegemônico de dominação cultural; “ideologia desertificadora" apoiado no capitalismo, no colonialismo e no paternalismo, e coloca a questão: "Quais são as ideias que dispomos no início da terceira década do século XXI para analisarmos o que tem se passou sobretudo nas últimas décadas na América Latina e nos orientar para onde começa?" Como desmontar a ideia de inevitabilidade das mazelas causadas por esse triunvirato que tanto mal tem causado ao mundo e especialmente aos países do "Sul"? Boaventura sugere que as ideias sejam concebidas segundo um paradigma artístico; "estas instalações pedagógicas pretendem ser performativas, recorrem ao passado como se este nunca houvesse ocorrido e ao futuro como se estivesse aqui" (tradução nossa). ${ }^{5}$

5 O texto na língua espanhola é: “(...) estas instalaciones pedagógicas pretenden ser performativas, recurren al passado como si este nunca hubiera sucedido y al futuro como si estuviera aqui." 
Paul B. Preciado, Achille Mbembe, Boaventura de Souza Santos e Ailton Krenak continuam observando, refletindo e escrevendo nesse momento sobre as implicações sanitárias e desdobramentos da pandemia do coronavírus e os afetos sobre a humanidade visto que o SARS-coV-2 continua ativo no planeta, e nós seguimos em isolamento temendo o contágio.

\section{Referências}

AGAMBEN, G. O que é o contemporâneo? e outros ensaios. Chapecó, SC: Argos, 2009, pp. 55-73.

BARBOSA, J.; TEIXEIRA, L.; BRAGA, A. Cartografia Social da Covid19 na cidade do Rio de Janeiro. Disponível em: https://of.org.br/noticias-analises/cartografia-social-da-covid-19-na-cidade-do-rio-de-janeiro/. Acesso em 27 agosto 2020.

BOND, L. Casos de feminicídio crescem 22\% em 12 estados durante a pandemia. Agência Brasil. Brasília, D.F., jun.2020. Disponível em: https:// agenciabrasil.ebc.com.br/direitos-humanos/noticia/2020-06/casos-de-feminicidio-crescem-22-em-12-estados-durante-pandemia Acesso em: 04 setembro 2020.

FOUCAULT, M. Vigiar e punir: nascimento da prisão. Petrópolis: Rio de Janeiro: Vozes, 1987.

KRENAK, A. Ideias para adiar o fim do mundo. São Paulo: Companhia das Letras, 2019.

. O amanhã não está à venda. São Paulo: Companhia das Letras, 2020.

LÖWY, Michael. Walter Benjamin: aviso de incêndio: uma leitura das teses "Sobre o conceito de história". São Paulo: Boitempo. 2005, pp. 65-69.

MBEMBE, Achille. O direito universal a respiração. Disponível em: http:// www.ihu.unisinos.br/78-noticias/598111-o-direito-universal-a-respiracao-artigo-de-achille-mbembe Acesso em 17 ago. 2020.

MORAES, E. R. de. O corpo impossível. São Paulo: Iluminuras, 2002.

PRECIADO, Paul B. Aprendendo com o vírus. Associação dos Geógrafos Brasileiros. Campinas, 28/mar/2020. Disponível em: http://agbcampinas.com. $\mathrm{br} /$ site/2020/paul-b-preciado-aprendendo-com-o-virus/ Acesso em 14 ago. 2020. 
SOUSA SANTOS, B. de. O coronavírus, nosso contemporâneo. Revista de Letras. Portugal. 6 - 19 maio 2020. Disponível em: http://www.boaventuradesousasantos.pt/media/Boaventura_0\%20coronav\%C3\%ADrus\%20nosso\%20 contempo\%C3\%A2neo 6Maio2020.pdf. Acesso em 21 ago. 2020.

Souza Santos, Boaventura de. Para alimentar la llama de la esperanza. Revista Casa de las Américas, n. 298, enero-marzo/2020, p.5 (pdf.). Disponível em: http://www.boaventuradesousasantos.pt/media/ Para\%20alimentar\%20la\%20llama\%20de\%20la\%20esperanza CasaAm\%C3\%A9ricas 2020.pdf Acesso em 29 set. 2020

\section{Outras fontes}

FIOCRUZ - Fundação Oswaldo Cruz https://portal.fiocruz.br/. Acesso em 09 set. 2020.

OPAS - Organização Pan-americana de Saúde https://www.paho.org/bra/. Acesso em 09 set. 2020.

ESTADO DE MINAS - https://www.em.com.br/app/noticia/nacional/2020/09/15/interna nacional,1185431/seca-e-o-fogo-criminoso-devastam-quase-todos-os-biomas-do-brasil.shtml

Recebido em 25 de setembro de 2020 e aceito em 06 de março de 2021.

Este é um artigo publicado em acesso aberto sob uma licença Creative Commons

(cc) $\mathrm{Br}$ 